\title{
Simulating North American mesoscale convective systems with a convection-permitting climate model
}

\author{
Andreas F. Prein ${ }^{1}\left(\mathbb{D} \cdot\right.$ Changhai Liu $^{1} \cdot$ Kyoko Ikeda $^{1} \cdot$ Randy Bullock $^{1} \cdot$ \\ Roy M. Rasmussen ${ }^{1}$ - Greg J. Holland ${ }^{1} \cdot$ Martyn Clark $^{1}$
}

Received: 16 March 2017 / Accepted: 26 September 2017 / Published online: 28 October 2017

(c) The Author(s) 2017. This article is an open access publication

\begin{abstract}
Deep convection is a key process in the climate system and the main source of precipitation in the tropics, subtropics, and mid-latitudes during summer. Furthermore, it is related to high impact weather causing floods, hail, tornadoes, landslides, and other hazards. State-of-the-art climate models have to parameterize deep convection due to their coarse grid spacing. These parameterizations are a major source of uncertainty and long-standing model biases. We present a North American scale convection-permitting climate simulation that is able to explicitly simulate deep convection due to its $4-\mathrm{km}$ grid spacing. We apply a feature-tracking algorithm to detect hourly precipitation from Mesoscale Convective Systems (MCSs) in the model and compare it with radar-based precipitation estimates east of the US Continental Divide. The simulation is able to capture the main characteristics of the observed MCSs such as their size, precipitation rate, propagation speed, and lifetime within observational uncertainties. In particular, the model is able to produce realistically propagating MCSs, which was a long-standing challenge in climate modeling.
\end{abstract}

This paper is a contribution to the special issue on Advances in Convection-Permitting Climate Modeling, consisting of papers that focus on the evaluation, climate change assessment, and feedback processes in kilometer-scale simulations and observations. The special issue is coordinated by Christopher L. Castro, Justin R. Minder, and Andreas F. Prein.

Electronic supplementary material The online version of this article (doi:10.1007/s00382-017-3993-2) contains supplementary material, which is available to authorized users.

Andreas F. Prein

prein@ucar.edu

1 National Center for Atmospheric Research, 3090 Center Green Drive, Boulder, CO 80301, USA
However, the MCS frequency is significantly underestimated in the central US during late summer. We discuss the origin of this frequency biases and suggest strategies for model improvements.

Keywords Mesoscale convective systems - Convectionpermitting climate modeling $\cdot$ Strom tracking $\cdot$ North America $\cdot$ Precipitation extremes

\section{Introduction}

Deep convection is a common ingredient of many atmospheric extreme events and causes weather-related hazards globally (e.g., Doswell III et al. 1996; Kunkel et al. 2012). Deep convection causes major societal impacts due to flooding, wind gusts, hail, tornadoes, landslides, and debris flows. It is essential for hydrology since it is the dominant source of precipitation in the tropics, subtropics, and mid-latitudes during summertime (Yang and Smith 2008). For example, half of the summertime rainfall in the US plains originates from deep convective systems (Jiang et al. 2006).

State-of-the-art climate models are not able to represent convective precipitation explicitly because of their coarse grid spacing [larger than $12 / 100 \mathrm{~km}$ in regional/global climate models; Taylor et al. (2012)/Jacob et al. (2014)]. These models rely on convection parameterization schemes that are major sources of errors and uncertainties (e.g., Déqué et al. 2007). Recently, increasing computational resources made convection-permitting climate simulations (CPCSs) feasible that operate on horizontal grids $<4 \mathrm{~km}$ (e.g., Prein et al. 2015) and enable the explicit simulation of deep convection.

An advantage of CPCSs is their ability to improve the simulation of the convective precipitation diurnal cycle [see Prein et al. (2015) for a review]. This demands a realistic 
simulation of the evolution and propagation of deep convection. Our $4 \mathrm{~km}$ grid spacing model is too coarse to realistically simulate single cell thunderstorms, however, Mesoscale Convective Systems [MCSs, Houze (2004)] that consist of a complex of thunderstorms that become organized, can be captured. In North America, these storms include squall lines (Rotunno et al. 1988), which are storms arranged in a line along a evaporatively generated near-surface cold outflow and Mesoscale Convective Complexes with a large circular cloud shield (Maddox 1980). Despite the advantages of CPCSs, a kilometer scale horizontal grid spacing can only resolve large-scale convective motions and has been shown to result in large convective cells that do not entrain midlevel air (Bryan and Morrison 2012). A more realistic simulation of turbulent entrainment and up/down drafts would demand reducing the grid spacing by an order of magnitude, which is not affordable with current computer resources.

To identify MCSs in observations and our simulation we use a new variation of afeature-based verification method called the method for object-based diagnostic evaluation (MODE) (Davis et al. 2006, 2009) that incorporates the time dimension [MODE time-domain or short MTD; Clark et al. (2014)]. MTD is part of the Developmental Testbed Centers (DTC) Model Evaluation Tools (MET; the current version is available online at http://www.dtcenter.org/met/ users/downloads/). MTD outputs all basic statistics included in MODE such as object size, location, and orientation, as well as information on the entire life cycle of objects including speed, changes in size and intensity, lifetime, and track length.

MODE has been used successfully to detect biases in short-term weather forecasts (e.g., Davis et al. 2006, 2009; Clark et al. 2012; Mittermaier and Bullock 2013). It was reported that coarse-resolution forecast models produce too many large rain areas and underestimate rainfall intensities (e.g., Davis et al. 2006; Wernli et al. 2008). Convectionpermitting weather forecasts show substantial improvements over coarse-resolution forecasts and reduce the size and intensity biases (Wernli et al. 2008; Davis et al. 2009). Similar improvements are found in CPCSs (Prein et al. 2013a; Brisson et al. 2015).

Using a feature-tracking algorithm, Chang et al. (2016) evaluated a $12 \mathrm{~km}$ resolution climate model simulation during June, July, and August (JJA) over the US and found similar model biases as in low-resolution weather forecasts, i.e., an underestimation of hourly precipitation intensities and an overestimation of the rainfall area. Using the MTD tracking algorithm, Clark et al. (2014) showed that convectionpermitting weather forecasts are able to capture the spatial distribution, lifetime, and the diurnal cycle of MCSs but underestimate their translation speed.

In this manuscript we will assess if CPCS are able to simulate MCSs in a similar quality than short-term numerical weather forecasting models. The goal is to understand if CPCS can be used to analyze the impact of climate variability and climate change on North American MCSs.

\section{Data and methods}

\subsection{Model setup and observational data}

The Weather Research and Forecasting (WRF) model Version 3.4.1 (Skamarock and Klemp 2008) is used to downscale the European Centre for Medium-Range Weather Forecast Interim Reanalysis (ERA-Interim) (Dee et al. 2011) over large parts of North America to 4-km horizontal grid spacing (Liu et al. 2016; see Fig. 1). The model domain has a size of $1360 \times 1016$ grid points and 51 stretched vertical levels topped at $50 \mathrm{hPa}$. The simulation covers 13 water years starting in October 2000 and ending in September 2013.

The main physics packages used in our WRF simulation are the Thompson aerosol-aware microphysics (Thompson and Eidhammer 2014), the Yonsei University (YSU) planetary boundary layer scheme (Hong et al. 2006), the Rapid Radiative Transfer Model (RRTMG) (Iacono et al. 2008), and the improved Noah-MP land surface model (Niu et al. 2011). Additionally, an upgraded lake water temperature treatment is implemented and spectral nudging (von Storch et al. 2000; Miguez-Macho et al. 2004) of temperature, horizontal wind speed, and geopotential height is applied. Only wavelengths larger than $\sim 2000 \mathrm{~km}$ above the planetary boundary layer are nudged with a moderate nudging strength (coefficient) corresponding to an e-folding time of about 6-h (Liu et al. 2016). The nudging ensures that synoptic-scale

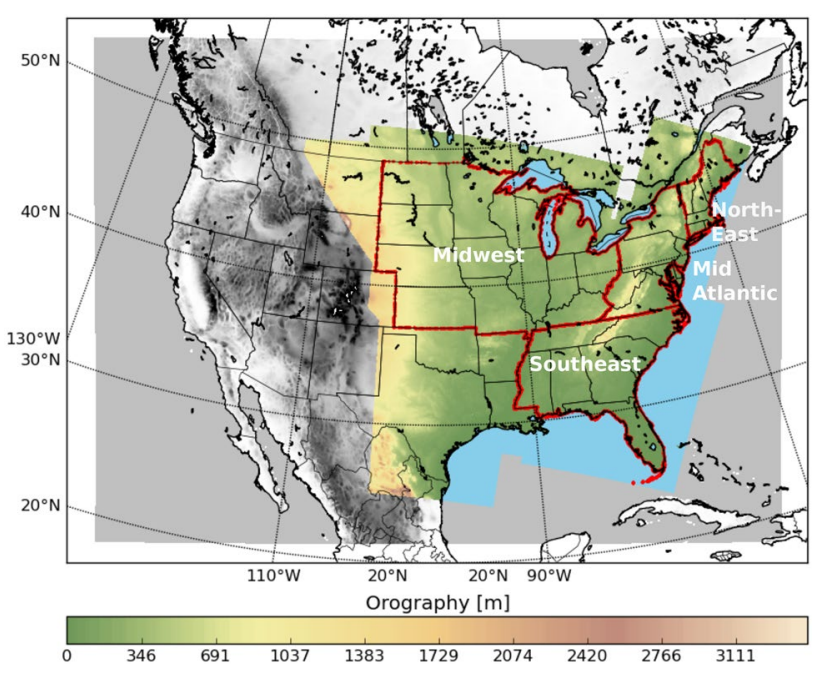

Fig. 1 Filled contours showing the model orography in the simulation domain (gray area) and the evaluation region (colored area). The red polygons show the outlines of the investigated climate regions. The computational domain contains $1360 \times 1016 \times 51$ grid cells 
features are similar to the observations while sub-synopticscale processes such as the upscale growth and organization of MCSs can freely evolve. The final model setup is based on a series of sensitivity test that incorporated model physics (Liu et al. 2011, 2016) and model grid spacing (Ikeda et al. 2010; Prein et al. 2013b). Additional information about the simulation can be found in Liu et al. (2016).

This simulation was evaluated in previous studies that found overall good performance in capturing the annual/ seasonal/sub-seasonal precipitation and surface temperature climatology except for a summer dry and warm bias in the Central US, wet biases in the Southeast and Southwest during summer, and a dry bias in the Deep South (Liu et al. 2016). JJA hourly precipitation extremes, defined as the 99.95 percentile of dry and wet hours, are underestimated by $30 \%$ except along the Gulf and Atlantic coastline (Prein et al. 2017).

For the model evaluation, we use the National Centers for Environmental Prediction (NCEP) stage-IV analysis (Fulton et al. 1998; Nelson et al. 2016) that provides hourly precipitation on a 4-km Contiguous United States (CONUS) grid based on radar and gauge reports. Since stage-IV has quality issues over the western half of the CONUS, over ocean regions, and prior to 2002 [e.g., Nelson et al. (2016)] we decided to constrain the analysis to land regions east of the Continental Divide for the period January 2002 to September 2013 (see colored area in Fig. 1). For the MTD analysis, we regrided the simulated precipitation field to the stage-IV grid by conserving total precipitation. Then we applied the mask shown in Fig. 1 to the stage-IV and the modeled hourly precipitation. As a final step, we masked all grid cells in the model data that are flagged as missing in stage-IV. We performed this data preprocessing to minimize the effect of errors and limitations of the observations on our results.

\subsection{MODE time domain (MTD)}

MTD automatically identifies objects in a spatial field and tracks them over time. MCSs can be identified in multiple atmospheric fields such as mid-tropospheric vorticity (Wang et al. 2011), cloud-related fields such as cloud top temperatures (Feng et al. 2016), or precipitation (Clark et al. 2014). Here we use hourly precipitation because of its high socioeconomic relevance and the availability of the stageIV dataset that allows a sound model evaluation. Note that MCS characteristics depend on the investigated variable. For example, tracking MCS precipitation will typically lead to shorter MCS lifetimes than tracking mid-tropospheric vorticity.

In the first step, MTD smooths hourly precipitation fields by averaging over all grid cells within a user-defined squared smoothing radius. The smoothing makes the precipitation areas more contiguous and helps to filter out small, weak storms that are smaller than the effective resolution (four to eight times the horizontal grid spacing) of the simulation. The second MTD step involves the application of a user-defined threshold to the smoothed field. All precipitation values below this threshold are masked. The smoothing and thresholding result in only identifying MCSs whereas smaller storms such as airmass convection and supercell thunderstorms that are not well resolved by the model, are masked. In the third step, contiguous precipitation regions are identified and are assigned to an identifying number. Contiguous precipitation areas are defined as grid cells that are adjacent in space and time (plus or minus one time step). A more detailed description of MTD can be found in the MET Users Guide (http://www.dtcenter.org/met/users/docs/ users_guide/MET_Users_Guide_v6.0.pdf).

Most results presented in this study are derived by using a smoothing radius of eight grid cells $(\sim 32 \mathrm{~km})$ and a threshold of $5 \mathrm{~mm} \mathrm{~h}^{-1}$ on hourly precipitation accumulations (except otherwise noted). To test the sensitivity of our results to the MTD settings we repeated all analyses with a threshold of $2.5 \mathrm{~mm} \mathrm{~h}^{-1}$ and smoothing radii of 16 and 32 grid cells. The impacts of these settings are discussed and examples are shown where needed. In general, increasing the smoothing radius and the threshold leads to fewer and smaller objects. As an additional constraint, we only analyze $3 \mathrm{D}$ objects that have a minimum volume of 2000 grid cells with precipiation above the threshold, which results in the detection of moderate to large-scale MCSs that have a lifetime of several hours up to days (e.g., a lifetime of $10 \mathrm{~h}$ and an average area of $3200 \mathrm{~km}^{2}, 15 \times 15$ grid cells). Because of limited computational resources, we had to perform MTD analyses on a monthly basis. This means that an object that begins on the last day of a month and continue into the first day of the next month is treated as two separate objects. The effect on our results should be nonsystematic and nonsignificant because the truncation only occurs every $\sim 700$ time steps (hours in a month) whereas the lifetime of MCSs is on average $\sim 10 \mathrm{~h}$.

Since we are evaluating climate simulations we do not demand that individual MCSs are correctly captured by our model. Instead, we assess the model's ability to reproduce the observed MCS climatology in four climate regions: Midwest, Southeast, Mid-Atlantic, and Northeast (Fig. 1). An MCS is assigned to the climate region where it spends more than half of its lifetime in terms of location of the MCS center.

An example MTD analysis of an observed and modeled MCS that occurred on 12 March 2007, in Texas is shown in Fig. 2. The maps show the MCS at different stages of its lifetime from one hour after its origin to its dissolution more than $20 \mathrm{~h}$ later (Fig. 2a, c). The system originated from multiple isolated small cells. After $6 \mathrm{~h}$ the scattered convective cells merged into a single object. At hour 21 the MCS weakened 

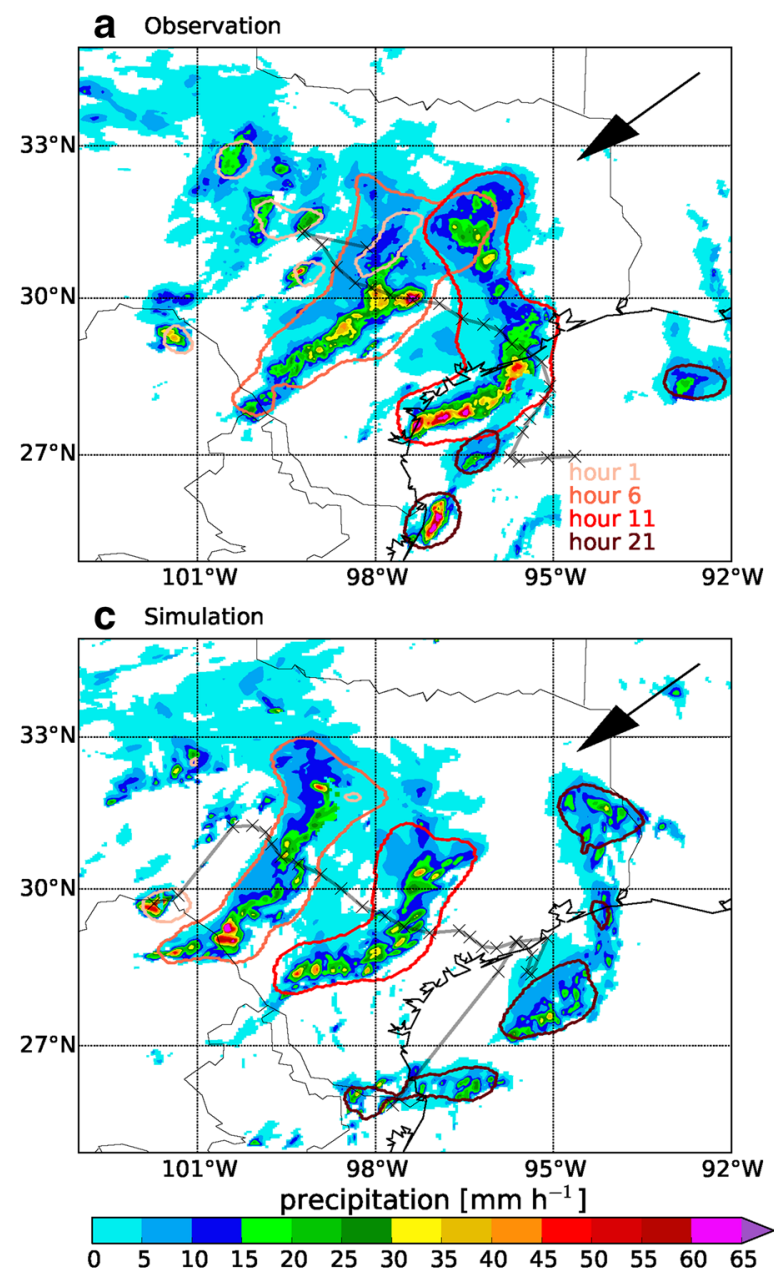

Fig. 2 An example for tracking an MCS with MTD that occurred on 12 March 2007, in Texas. Shown are observed (a) and modeled (c) hourly precipitation at the first, sixth, 11th, and 21st hour after the MCS genesis (light red to dark red contours detected by MTD in a, c). The MTD results of the temporal and spatial development of the b

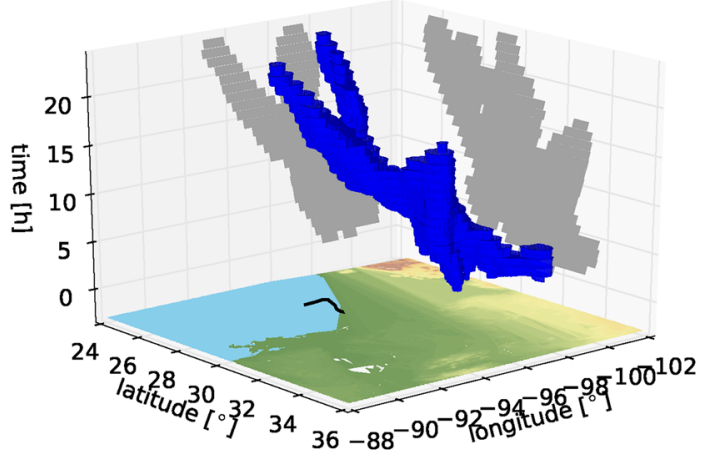

d

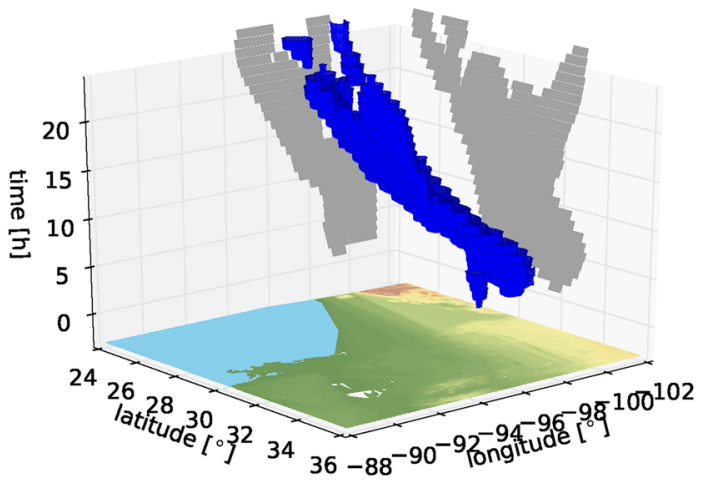

observed (b) and modeled (d) MCS precipitation shows a complex system of convection organization and dissolution. The arrow in the upper right corner $(\mathbf{a}, \mathbf{c})$ shows the direction of view in $\mathbf{b}$, and $\mathbf{d}$ and the gray shaded areas on the $x-z / y-z$ plane shows the projection of the MCS to the longitude/latitude axis

\section{Results}

model captures the main characteristics of the MCS well. Since we are investigating a climate simulation the aim is not to reproduce the observe storm perfectly but to show the model's ability to reproduce realistic MCS dynamics and precipitation structures. The three-dimensional representation of the MCS in Fig. 2b, d further highlights the similarity of the observed and modeled system and the capability of MTD in tracking complex MCSs. A 3-dimensional animation of the observed and simulated MCS can be found in the electronic supplement.

\subsection{MCS frequency, location, and movement}

All JJA observed and modeled MCS tracks between 2002 and 2013 are shown in Fig. 3a, b. The model is able to capture the observed gradient of maximum MCS precipitation with frequent intense MCSs (above $90 \mathrm{~mm} \mathrm{~h}^{-1}$ maximum) along the Gulf and southern Atlantic Coast region and a decrease in frequency and intensity inland and towards the north. The large number of MCSs allow us to perform 

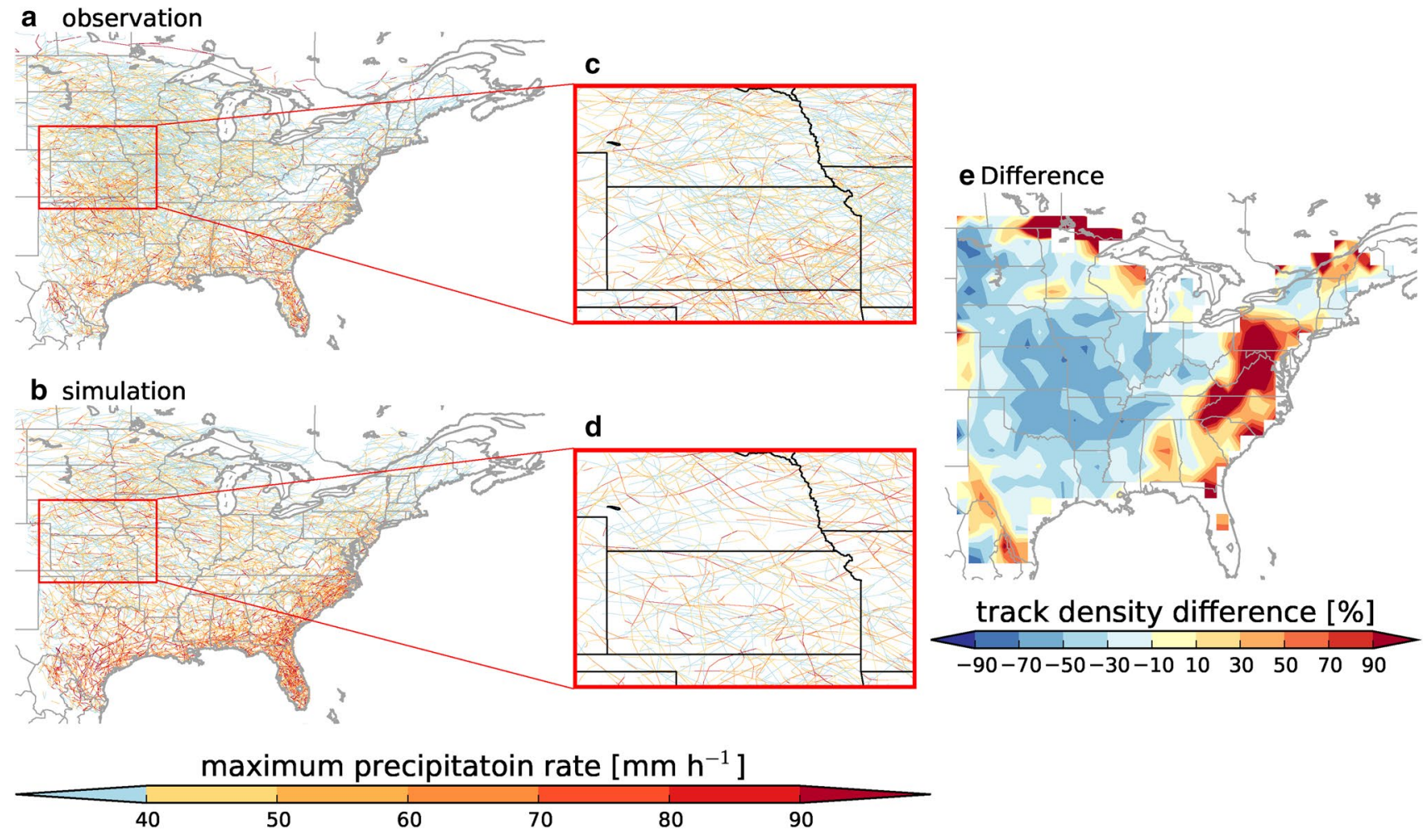

Fig. 3 Lines show observed (a) and modeled (b) MCS tracks in JJA and their color-coding corresponds to the MCS's maximum hourly precipitation. The insets (red box in $\mathbf{a}, \mathbf{b}$ ) show tracks in the central

statistically robust analyses. The simulation generally underestimates the MCS track density in the Central U.S. by up to $-70 \%$ (Fig. 3c-e). It overestimates the track density by more than $90 \%$ along the Southeast coast, the Appalachian region, and parts of the border to Canada. The overestimation can partly be attributed to deficiencies in the observational dataset since precipitation systems in the mountains are not well captured with US radars and the merging of Canadian radar data into the stage-IV dataset is error prone (Zhang et al. 2016). The biases in JJA track density are closely related to biases in mean precipitation, which is up to $50 \%$ underestimated in the central US and $50 \%$ overestimated in the Southeast and Mid-Atlantic region (Liu et al. 2016). The model performance in simulating MCS frequencies has a distinct annual cycle Fig. 4. The central US low bias emerges during July and August whereas biases in May and June are moderate. Frequency biases in the Southeast are always positive but also intensify in late summer.

Sensitivity analysis on the effects of the MTD threshold and smoothing radius are performed (Fig. 5). The basic bias patterns are similar for all setups but the biases clearly intensify if either the higher $\left(5 \mathrm{~mm} \mathrm{~h}^{-1}\right)$ threshold or a larger smoothing radius is used. This suggests that extremely strong and large MCSs are underrepresented in the central US and overestimated along the Gulf and Atlantic coast. The
US Relative differences in the MCS track densities (modeled minus observed MCSs crossing a $100 \mathrm{~km} \times 100 \mathrm{~km}$ region) are shown in $\mathbf{c}$

combination of a $5 \mathrm{~mm} \mathrm{~h}^{-1}$ threshold and a $128 \mathrm{~km}$ smoothing radius results in very few large and intense MCSs that do not allow robust statistical analysis because of their small sample size (Fig. 5f).

There is a pronounced diurnal cycle in the occurrence of observed MCSs with a nighttime maximum in the central US and daytime/afternoon maxima in coastal regions (Fig. 6a-d), consistent with the observed variation in precipitation (Dai et al. 1999). The model has a little nocturnal MCS activity in the central US but with a substantially lower amplitude (Fig. 6f, j). MCS amounts are overestimated along the Atlantic coast, especially in the Mid-Atlantic region during the afternoon (Fig. 6d, h, l). The pattern correlation coefficients between the observed and simulated MCS density are highest in the afternoon $(0.74$; Fig. $6 \mathrm{~d}$, h, 1) and lowest during the night ( 0.6 ; Fig. $6 \mathrm{~b}, \mathrm{f}, \mathrm{j})$. Model and observed MCS frequencies agree better when the diurnal cycle of occurrence probability is compared (see Fig. A1) since systematic frequency biases are not accounted for. This shows that the model is able to reproduce the phase of the MCS frequency diurnal cycle but has biases in capturing its amplitude.

The average MCS translation direction and speeds are comparable between the observation and simulation 

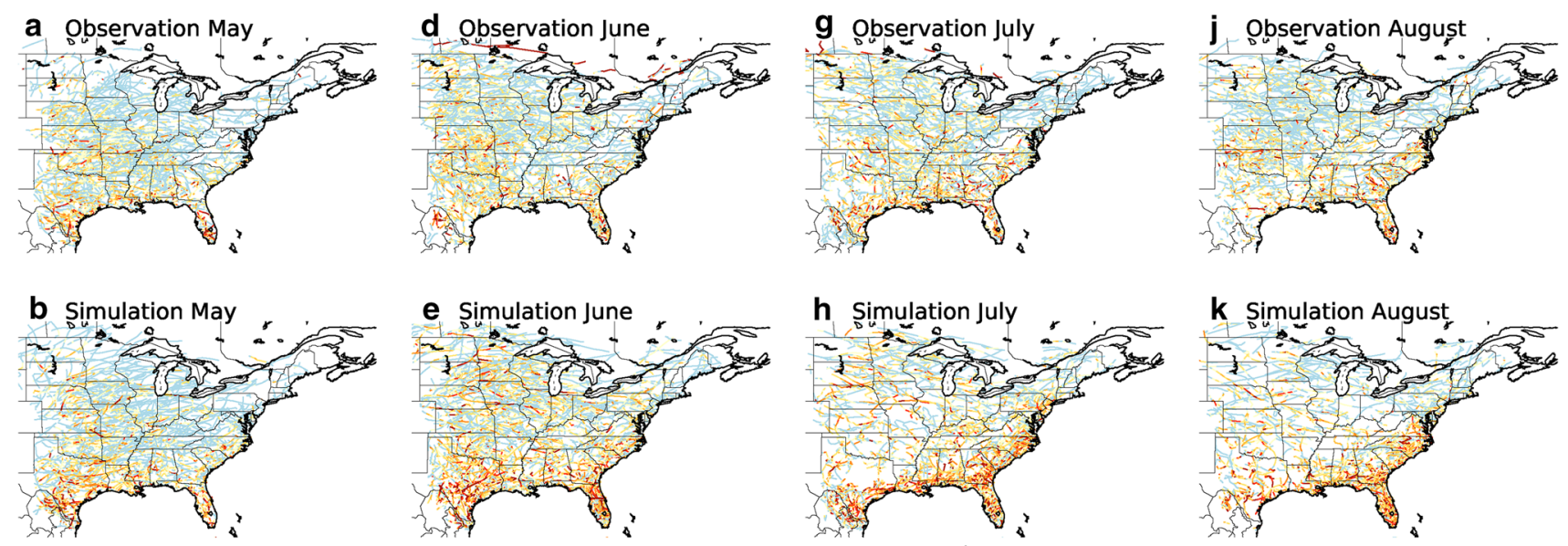

maximum intensity $\left[\mathrm{mm} \mathrm{h}^{-1}\right]$

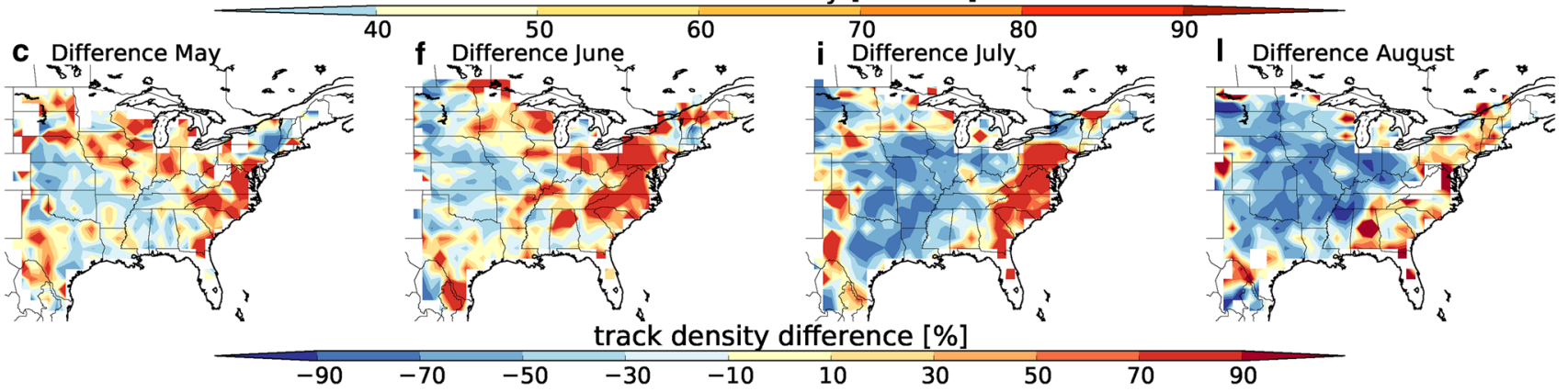

Fig. 4 As Fig. 3 but results are shown for MCSs in May, June, July, and August separately (left to right column)
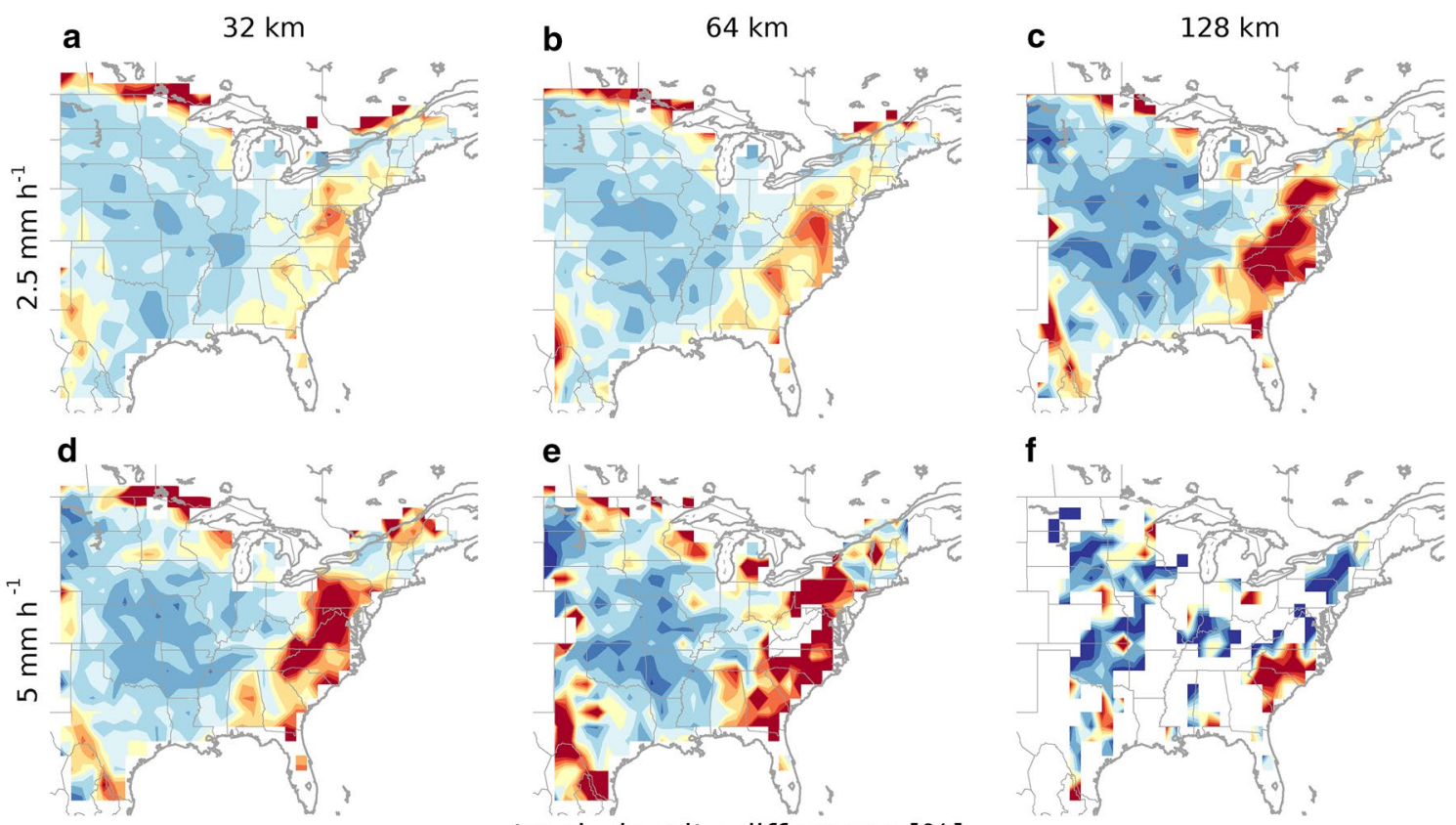

track density difference [\%]

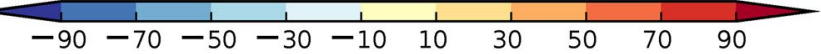

Fig. 5 As Fig. 3c but for MTD smoothing radius set to 8, 16, and $32 \mathrm{~km}$ (left to right) and the hourly precipitation threshold to $2.5 \mathrm{~mm} \mathrm{~h}^{-1}$ and $5 \mathrm{~mm} \mathrm{~h}^{-1}$ (top down) 

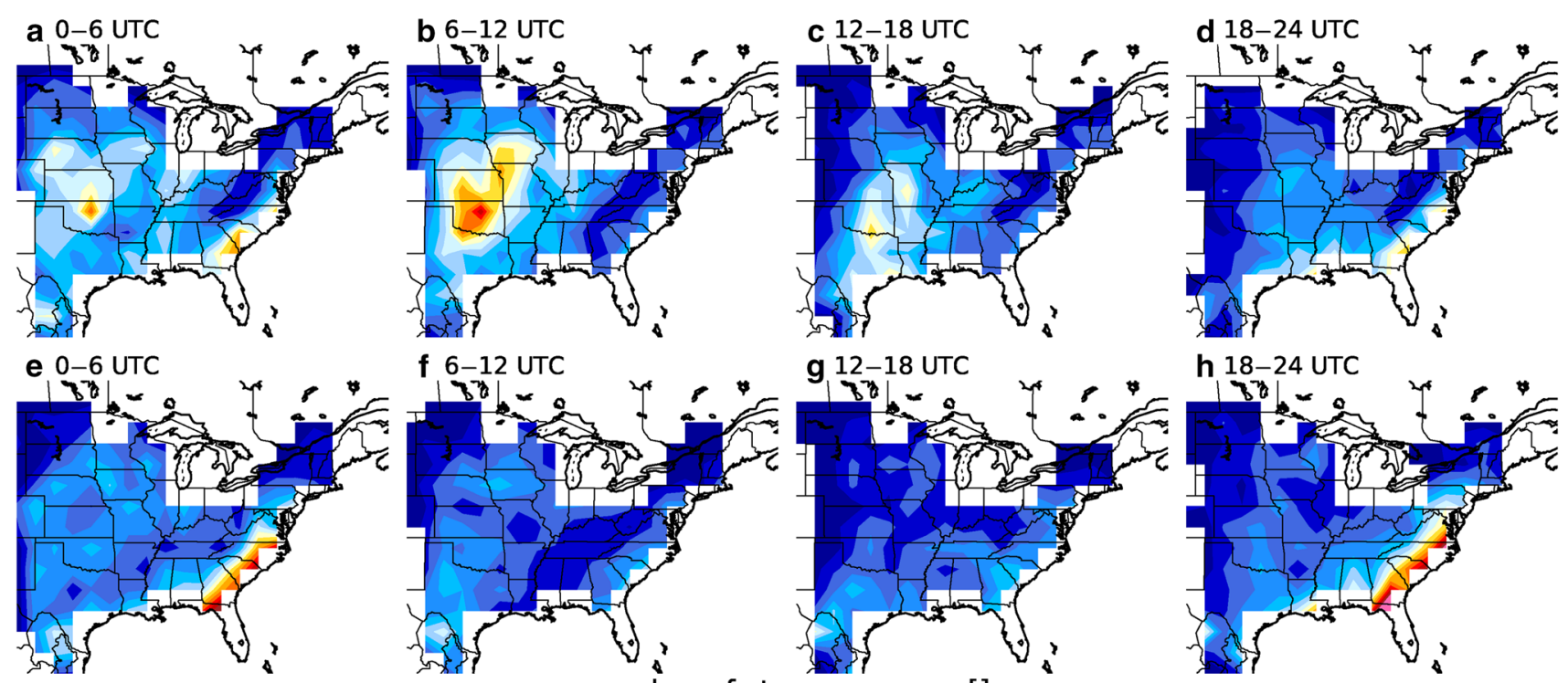

h $18-24$ UTC

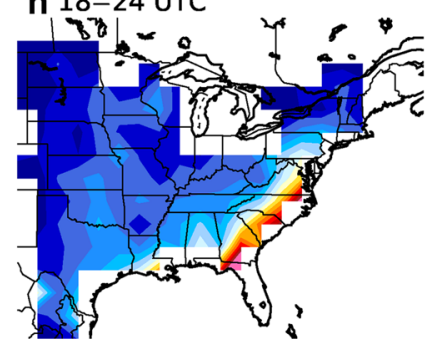

number of storm per year []

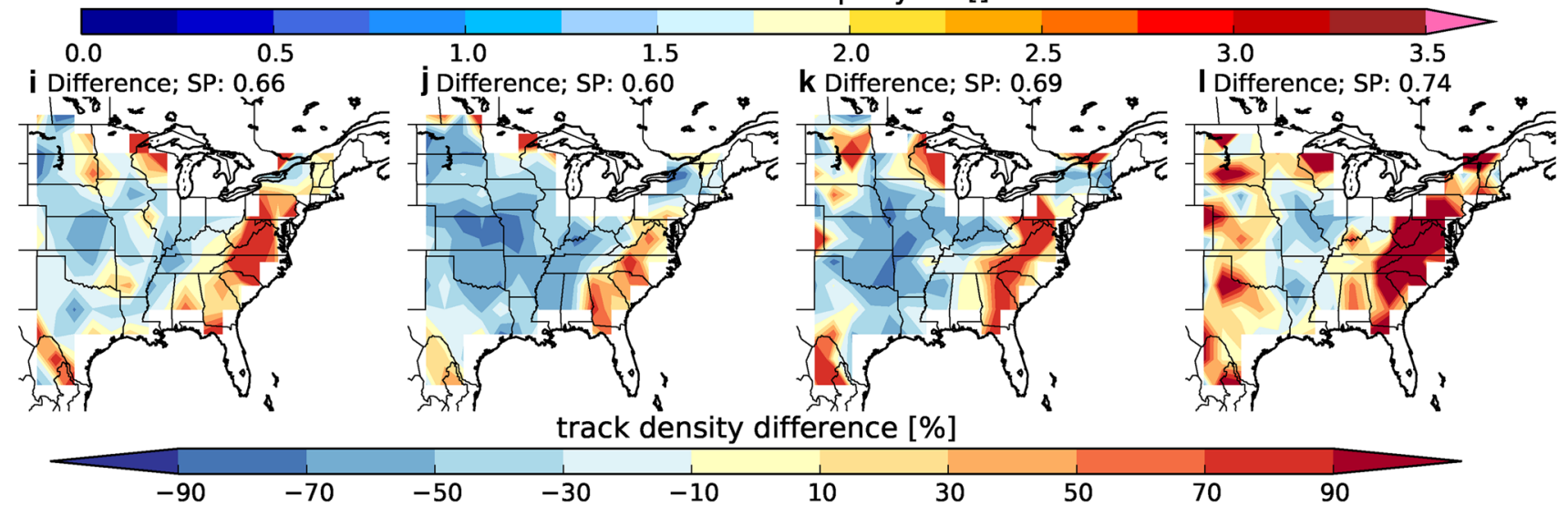

Fig. 6 MCS density in areas of $100 \times 100 \mathrm{~km}$ for all MCSs between 0-6 UTC (evening), 6-12 UTC (night), 12-18 UTC (morning), and 18-24 UTC (daytime) from left to right. Shown are the observed (a-d) and modeled (e-h) MCS density and their difference (i-e). The Spearman correlation coefficients (SP) is shown above the difference maps (i-l)
(Fig. 7a, b). Observed MCSs move eastward with velocities of $\sim 40-50 \mathrm{~km} \mathrm{~h}^{-1}$ in the northern part of the study region (above $\sim 40^{\circ} \mathrm{N}$ ). The MCS movement displays a southward component east of $\sim 90^{\circ}-\mathrm{W}$. In the southern part of the domain (below $\sim 40^{\circ}$ ) MCSs move slower with typical velocities below $30 \mathrm{~km} \mathrm{~h}^{-1}$. Over Texas, MCSs propagate southeast while east of the Appalachians MCSs move towards the northeast. The Appalachians are a transition region between the fast southeastward moving MCSs on the western side and the slower northeast-moving systems on the eastern side. Simulated MCSs propagate faster in the Northeast (at $\sim 44^{\circ} \mathrm{N}, \sim 72^{\circ} \mathrm{W}$ ) and the northeast movement east of the Appalachians is less pronounced (at $\left.\sim 37^{\circ} \mathrm{N}, \sim 82^{\circ} \mathrm{W}\right)$.

The hot-spots of MCS genesis are the found in the central U.S. and the eastern parts of South and North Carolina (Fig. 7c, d). The hot spot the eastern part of the Carolinas is captured in the simulation but the genesis frequency is overestimated. The missing genesis hot spot in the central US is clearly related to model deficiencies.

The simulated and observed number of MCSs are similar during winter and spring in the Midwest (Fig. 8b). However, simulated MCS occurrence rapidly decreases from June to July whereas observed MCS does not (see also Fig. 4). In July and August, the modeled MCS counts are $75 \%$ too low compared to the observations. A consequence of this bias is a significant underestimation of mean precipitation during July, August, and September (Fig. 8f; see also Liu et al. (2016)). Also, the ratio between MCS precipitation to total precipitation is too low (Fig. 8j). In the other regions, the differences are smaller and generally within the inter-annual variability. Results derived with a precipitation thresholds of $2.5 \mathrm{~mm} \mathrm{~h}^{-1}$ and different smoothing radii are similar. 

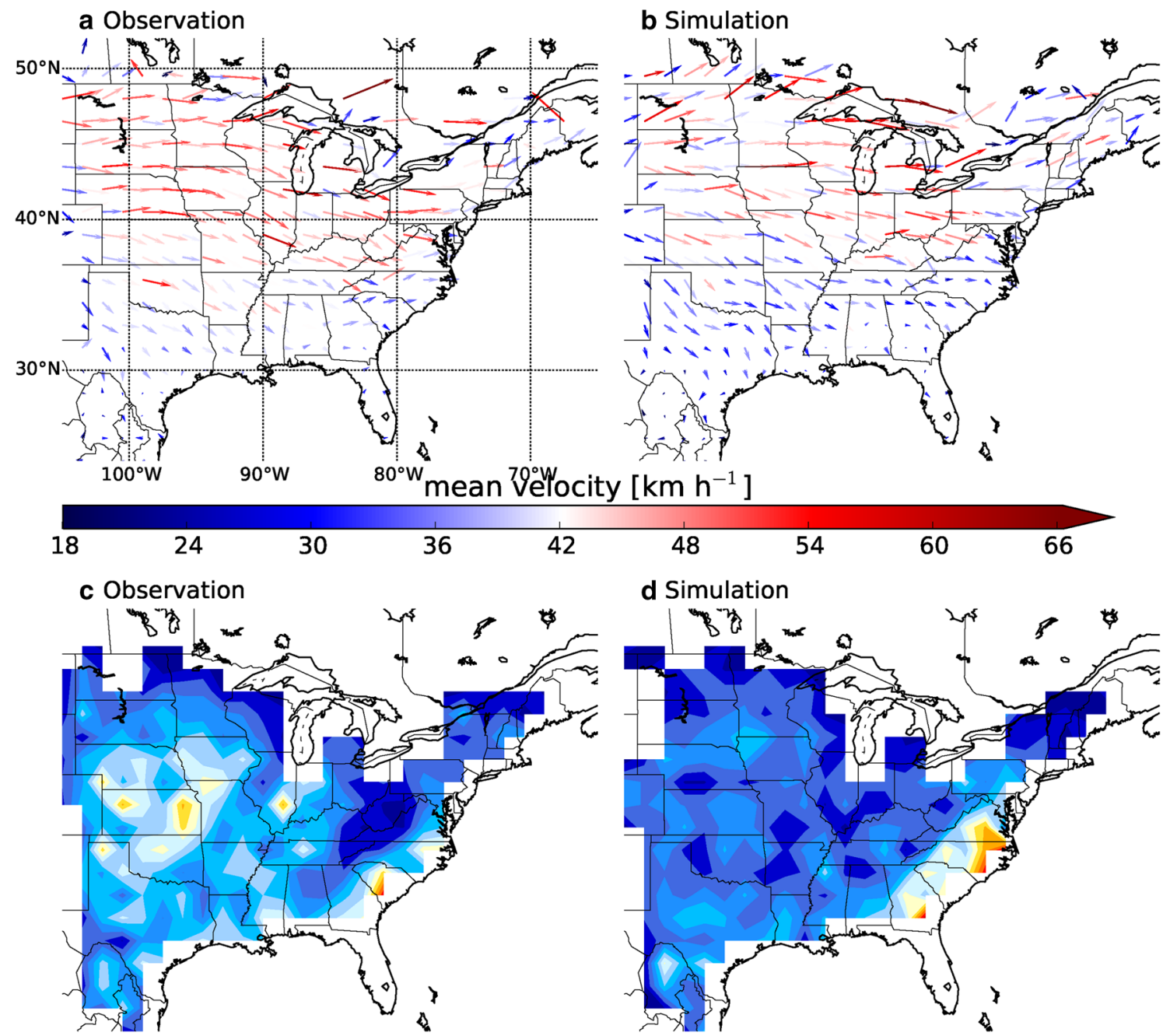

number of track geneses per year []

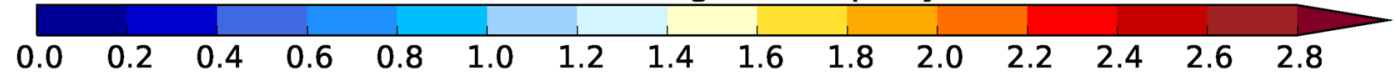

Fig. 7 Average observed and modeled (a, b) direction and speed of the MCS movement in $2^{\circ} \times 2^{\circ}$ regions indicated by the direction and length of arrows, respectively. The arrow color shows the mean speed of the MCSs. e.g., a short red arrow indicates MCSs that are fast but

\subsection{MCS characteristics}

Hourly precipitation snapshots of the eight most intense MCSs during JJA in the Midwest are shown in Fig. 9. The simulated MCSs (Fig. 9k-r) have realistic features, such as shape, size, and intensity, that are visually not distinguishable from observed MCSs (Fig. 9c-j). Note that this is a climatological viewpoint rather than a direct comparison as the observed and modeled MCSs occurred on different days. All modeled and observed MCSs reach precipitation maxima beyond $100 \mathrm{~mm} \mathrm{~h}^{-1}$. The observed and modeled size of the area where $60 \mathrm{~mm} \mathrm{~h}^{-1}$ is exceeded is on average $400 \mathrm{~km}^{2}$. Averaging the precipitation of the 40 observed MCSs with move in different directions while a blue long arrow shows slower MCSs that move in the same direction. $\mathbf{c}$ and $\mathbf{d}$ show the observed and modeled annual average number of MCS genesis in areas of 100 $\times 100 \mathrm{~km}$

highest maximum hourly precipitation indicates that MCSs typically have an oval shape with the main axis zonally rotated by $30^{\circ}$ (Fig. 9a). Note that parts of this shape can be attributed to the prevailing eastward movement of MCSs (see Fig. 7). The precipitation composit of the 40 most intense modeled MCSs is more circular and its main axis is $40^{\circ}$ and therefore slightly more tilted than in the observations. The composite mean intensities and the covered area are similar. MCss typically reach their maximum hourly rain rate during the first half of their lifetime after a phase of rapid intensification and organization of convection.

A more systematic comparison between the the modeled and observed MTD MCS characteristics in the four climate 

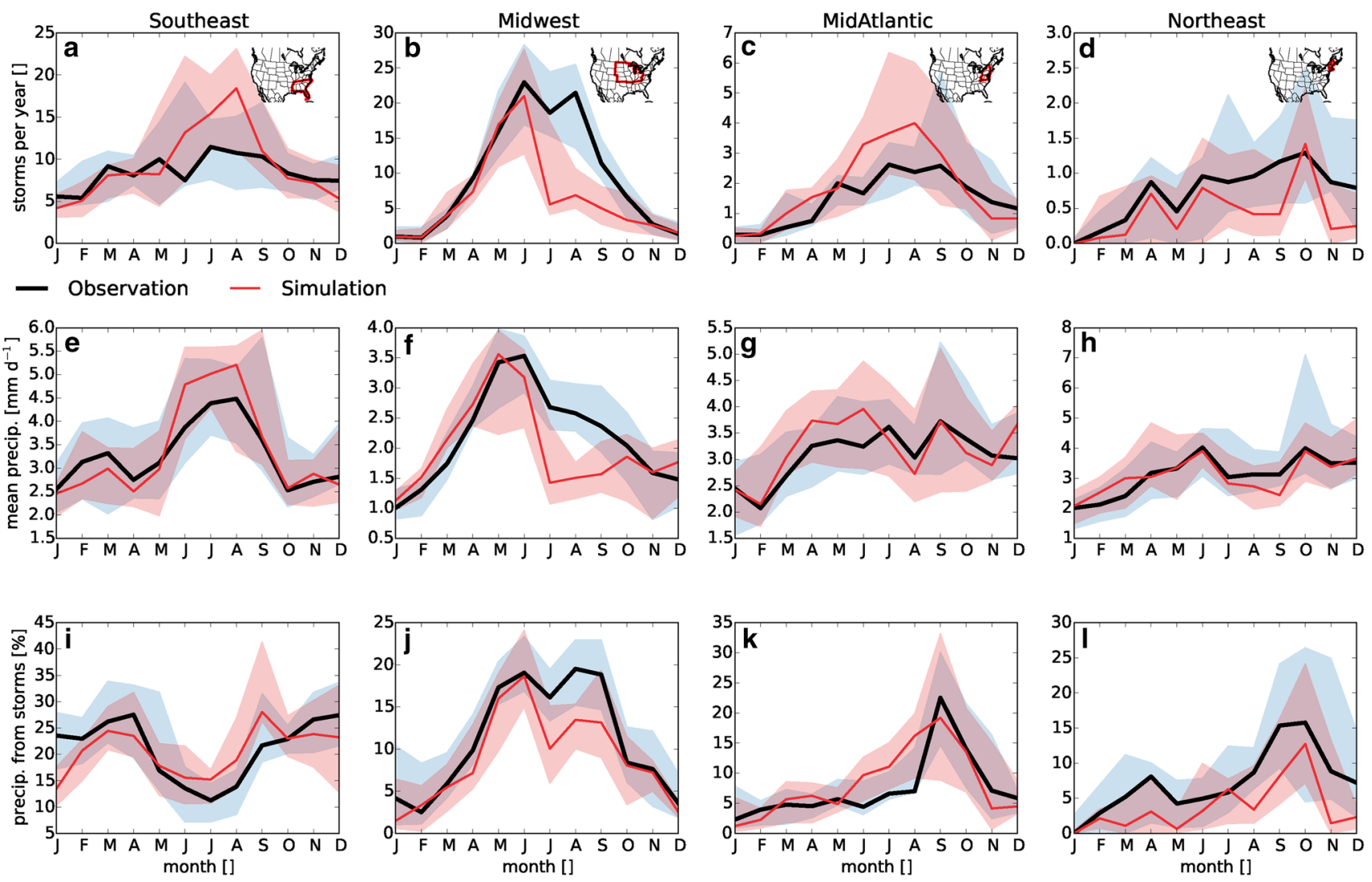

Fig. 8 The monthly mean annual cycle of the numbers of MCSs (a-d), mean precipitation (e-h), and percentage of precipitation from tracked MCSs relative to regional total monthly precipitation (i-l). Shown are the Southeast, Midwest, Mid-Atlantic, and North East

regions is shown in (Fig. 10). The size of the MCSs is very well captured especially in the Southeast (Fig. 10a) and Midwest region (Fig. 10b). Modeled MCSs tend to be too small in the Mid-Atlantic and Northeast region (Fig. 10c, d). However, some MCSs in the stage-IV observational dataset are spuriously large and intense in these regions and are likely erroneous. The typical precipitation areas have the size of small US states (e.g., Connecticut or Vermont; 10000 to $20000 \mathrm{~km}^{2}$ ).

The translation speed of the MCSs (movement of the MCS center from one hour to the next) is remarkably well simulated and no significant differences can be detected (Fig. 10e-h). The fastest MCSs occur in the Midwest region where propagation speeds of up to $100 \mathrm{~km} \mathrm{~h}^{-1}$ are observed and modeled while the slowest MCSs occur in the Southeast. The good agreement can partly be explained by the use of spectral nudging to observed large-scale flow patterns but are also related to the correct simulation of mesoscale dynamics as we will show later.

The simulated maximum MCS hourly precipitation is slightly overestimated but the differences are not significant except for the Southeast and Mid-Atlantic region

region (left to right). The shadings show the interquartile range of the interannual variability. Black lines and blue shading corresponds to the observations while red lines and shadings show simulated results

(Fig. 10i, k). Prein et al. (2017) showed that the model underestimates hourly extreme precipitation, defined as the 99.95 percentile of dry and wet hours, by up to $30 \%$ in the central US during summer. The advantage of the feature based evaluation presented here is that the individual components of the bias can be identified. The low bias shown in Prein et al. (2017) is caused by an underestimation of the frequency of MCSs. If maximum hourly precipitation from MCSs is evaluated the model overestimates the intensities by $5 \%$ to $25 \%$. This is in the range of observational uncertainties that are typically $\sim 20 \%$ caused by rain gauge under-catch (Duchon and Essenberg 2001).

The distribution of the MCS mean (Fig. 10m-p) and total precipitation (Fig. 10q-t) is also well captured by the model. The largest deviations occur in the Mid-Atlantic and Northeast region. Biases in the total precipitation are related to the biases in the MCS size (compare Fig. 10c, $\mathrm{d}$ with $\mathrm{s}, \mathrm{t}$ ). The model can simulate realistic MCSs with total precipitation values of up to $100000 \mathrm{~m}^{3} \mathrm{~s}^{-1}$, which is equivalent to half of the average discharge of the Amazon river or six times the discharge of the Mississippi. 


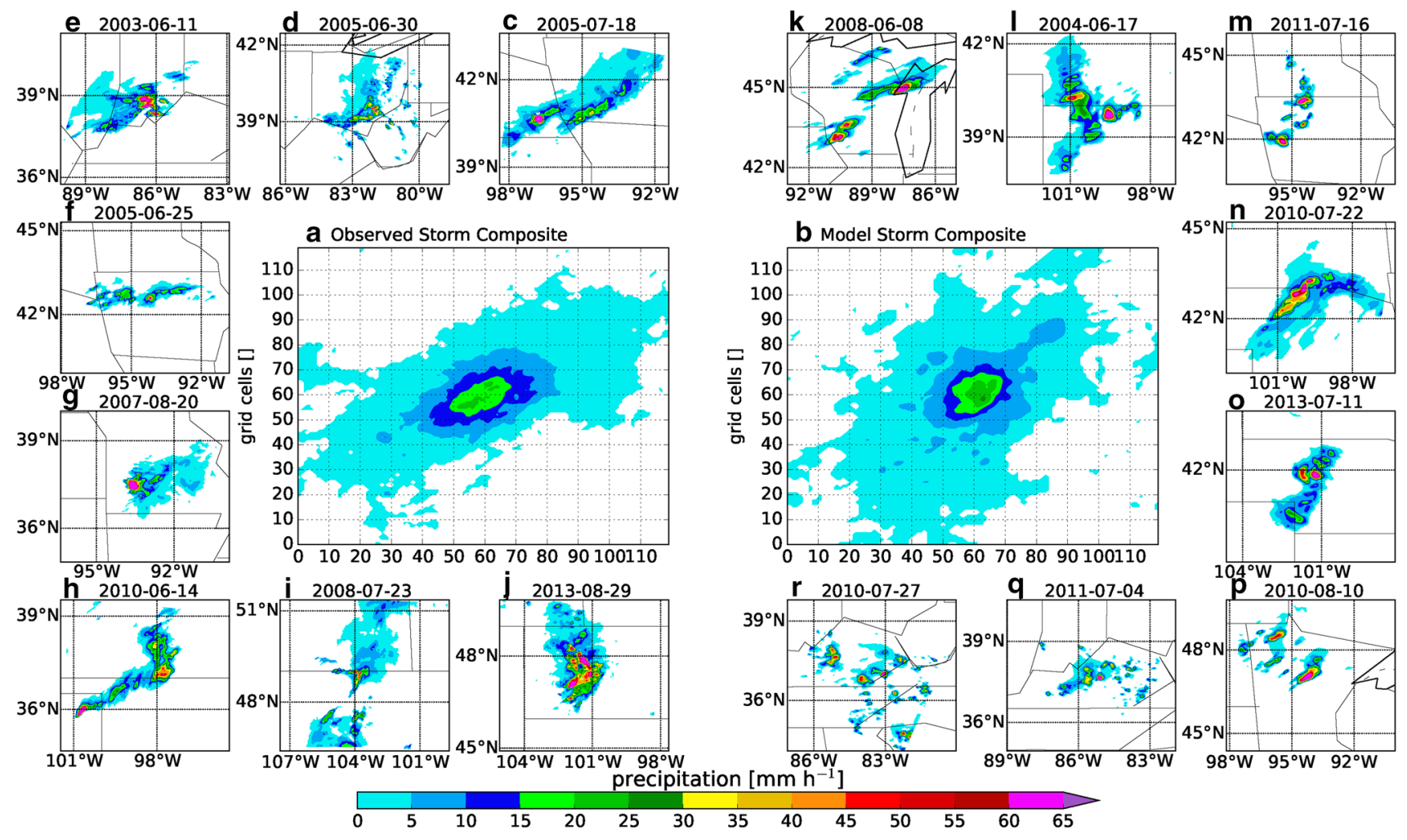

Fig. 9 Snapshots of hourly precipitation from the eight MCSs with highest hourly maximum precipitation rates in the Midwest during JJA in the observation (left panel; $\mathbf{c}-\mathbf{j}$ ) and the simulation (right panel; $\mathbf{k}-\mathbf{r}$ ). The dates of the extremes are shown above each panel. The average of the 40 MCS with highest maximum precipitation rates in the observation/model is shown in $\mathbf{a}$ or $\mathbf{b}$
The lifetime of MCSs is on average 10 hours but can reach more than a day in rare cases (Fig. 10u-x). The model almost perfectly reproduces MCS lifetimes in all regions. A similar performance can be seen for the track lengths of MCSs (Fig. 10y-B). Especially in the Midwest, MCSs can travel for vast distances of up to $1500 \mathrm{~km}$, which is a third of the east-west extent of the CONUS. The model's ability to simulate MCS characteristics typically deteriorates when a larger smoothing radii and the higher $\left(5 \mathrm{~mm} \mathrm{~h}^{-1}\right)$ threshold is used in MTD (Fig. A2) but Perkins skill scores (overlapping area of observed and modeled PDFs, Perkins et al. (2007)) are typically larger than 0.75 and show high model skills for all tested MTD settings.

Important for a realistic simulation of MCSs is not only the accurate simulation of single MCS characteristics but also the replication of their relationships. Generally, the model is able to reproduce the observed relationships very well in the Midwest region (Fig. 11). There is no correlation between the MCS speed and any other MCS property (Fig. 11a, c, e, h). The simulated maximum hourly precipitation is weakly correlated $(r=0.4)$ with MCS size, but the observations do not support this correlation (Fig. 11b). Maximum precipitation is also correlated with the mean precipitation (Fig. 11f) and total precipitation (Fig. 11i). The former relationship is non-linear, and the increase in maximum precipitation decrease at around $10 \mathrm{~mm} \mathrm{~h}^{-1}$ mean precipitation. This result is consistent in all regions (not shown). The highest correlation occurs between total precipitation and size with a correlation coefficient of 0.62 in the observations and 0.97 in the model. This high correlation is consistent with studies that showed a high correlation between the areatime integral of precipitation from convective storms and their rainfall volume (e.g., Doneaud et al. 1984; Lopez et al. 1989). This result might seem trivial since larger MCSs can precipitate more but the relationship is much less clear in the Southeast region and correlation coefficients are below 0.2 in the model and the observations (see Fig. A3). Varying the threshold and smoothing radius in the MTD analysis leads to very similar relationships between the object properties (not shown).

Finally, we analyze the dynamic evolution of the MCSs in the Midwest. There is a rapid intensification in the first hours after the MCS genesis in which the observed and modeled maximum precipitation increases by $50 \%$ (Fig. 12a). In their mature state, the MCS's maximum precipitation is almost constant for approximately $2-3 \mathrm{~h}$ in short-lived MCSs (lifetime $<10 \mathrm{~h}$ ) and rapidly decreases thereafter. Long-lived MCSs (lifetime $>10 \mathrm{~h}$ and $<10 \mathrm{~h}$ ) 

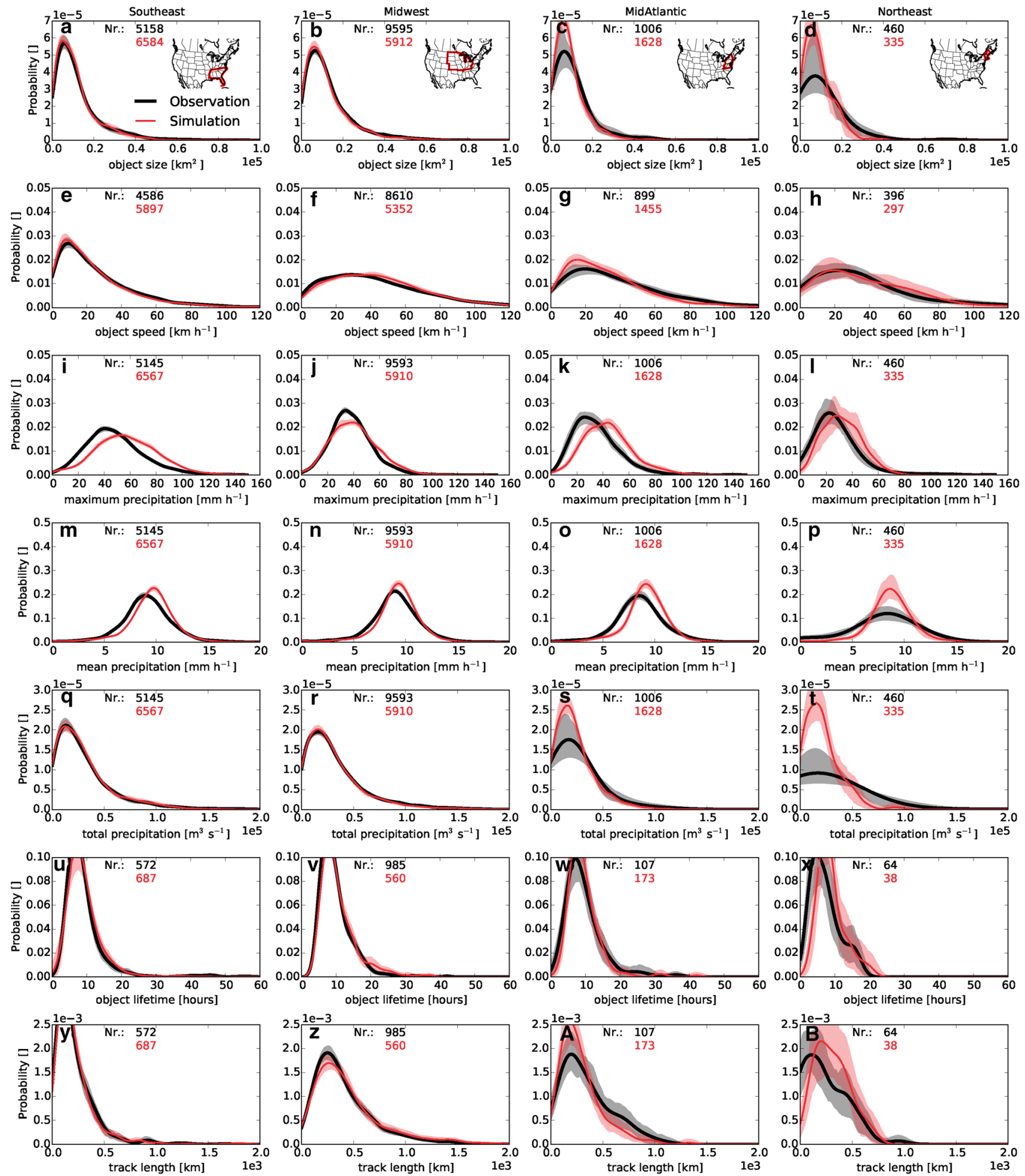

Fig. 10 Probability density functions (PDFs) for the hourly MCS size (a-d), speed (e-h), maximum precipitation (i-l), mean precipitation $(\mathbf{m}-\mathbf{p})$, and total precipitation $(\mathbf{q}-\mathbf{p})$. PDFs for the MCS lifetime and track length are shown in $\mathrm{u}-\mathrm{x}$ and $\mathrm{y}-\mathrm{B}$ respectively. Results for the Southeast, Midwest, Mid-Atlantic, and Northeast are shown from left to right (see inlays in $\mathbf{a}-\mathbf{d}$ ). The numbers in the panels denote the sample sizes that were used to construct the PDFs (black/red numbers show observation/model results). A Gaussian kernel density estimate was applied to estimate the PDFs from the empirical density functions. The shaded contours show estimates of the 1-99 percentile sampling uncertainty based on 100 bootstrap samples. Observed/ simulated results are shown in black/red 

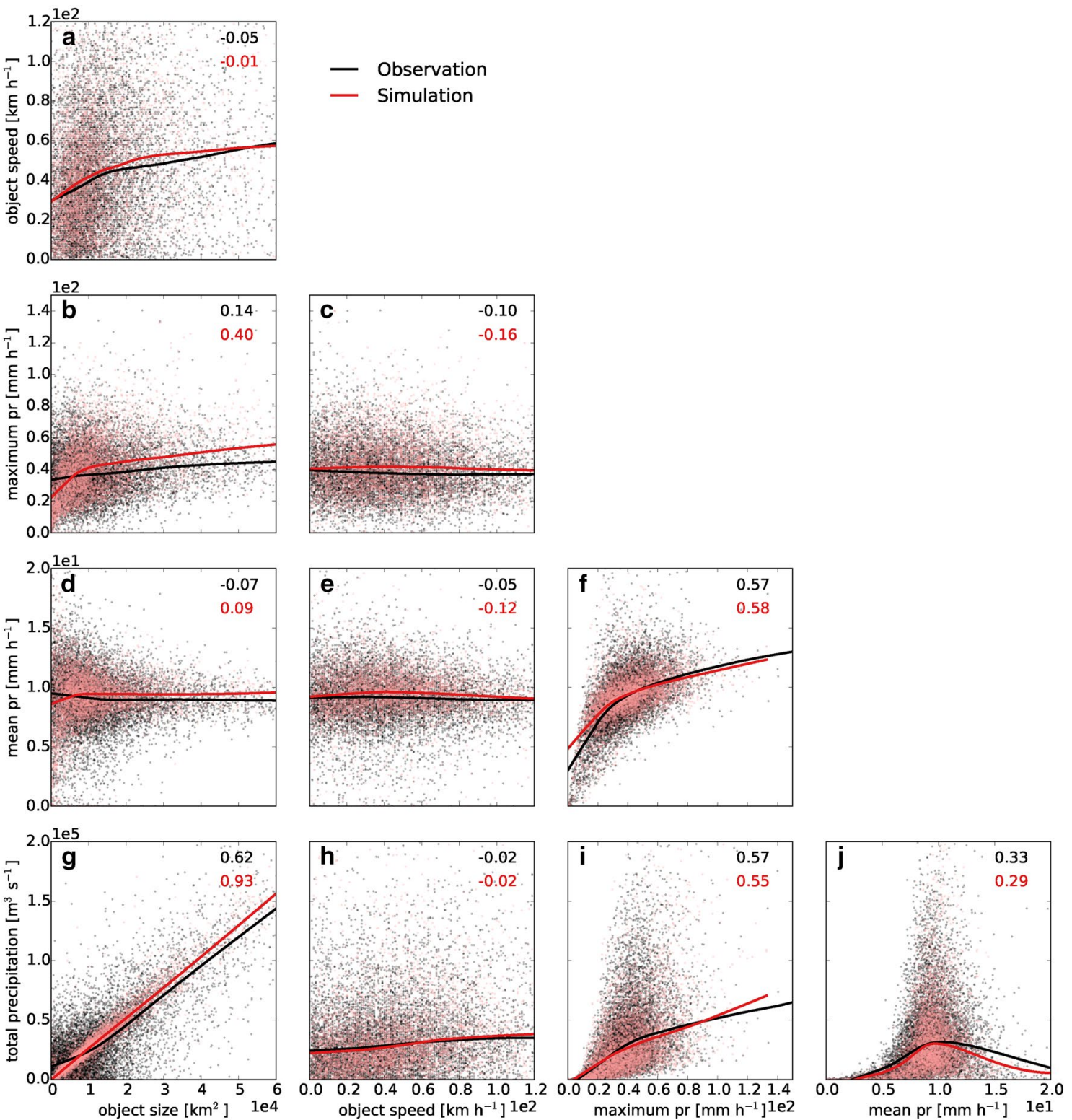

Fig. 11 Scatter plot matrix of MCS properties in the Midwest region. The numbers in the upper right of each panel show the Spearman's rank correlation coefficients and the lines show weighted linear

can maintain high precipitation intensities for up to $5 \mathrm{~h}$ and show a steady decay afterward. Also, the MCS size increases rapidly and shows more than a five-fold increase within the fist two hours after the MCS genesis (Fig. 12b). At this time short-lived MCSs reach their maximum size and start to steadily decay while long-lived MCSs continue growing for another $3 \mathrm{~h}$. The decay in MCS size occurs in conjunction with reduced maximum precipitation rates. There is a clear increase in MCS propagation speed during the intensification phase from $30 \mathrm{~km} \mathrm{~h}^{-1}$ to $45 \mathrm{~km} \mathrm{~h}^{-1}$ (Fig. 12c). Afterward, the speed stays approximately regression LOWESS curves (Cleveland 1979). Black/red colors show results from the observation/model

constant. This might be related to the progression of mesoscale organization of deep convection and evolving cold pool dynamics within the MCSs. Overall, the model closely reproduces the dynamical development of MCSs in the Midwest. This is very encouraging because it emphasizes that the model can capture fundamental processes such as the organization of convection and the interaction of mesoscale processes with the large scale flow realistically. Similar performances are found in other regions (see Fig. A4). 

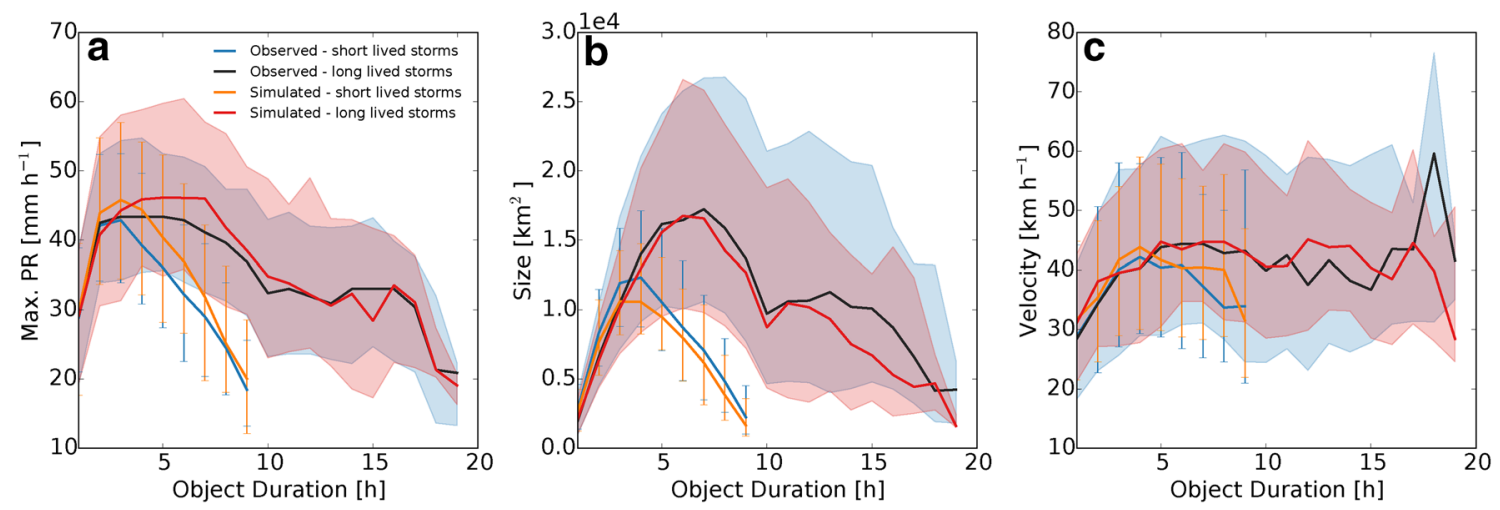

Fig. 12 Development of MCS maximum precipitation, size, and velocity (a-c) as a function of MCS duration in the Midwest region. Statistics for short-lived MCSs (blue/orange; lifetime shorter than $10 \mathrm{~h}$ ) and long-lived MCSs (red and black; lifetime between 10 and
$20 \mathrm{~h}$ ) are shown. The shading/error bars show the interquartile spread in the sample. Observed results are shown in cold colors and simulated results in warm colors
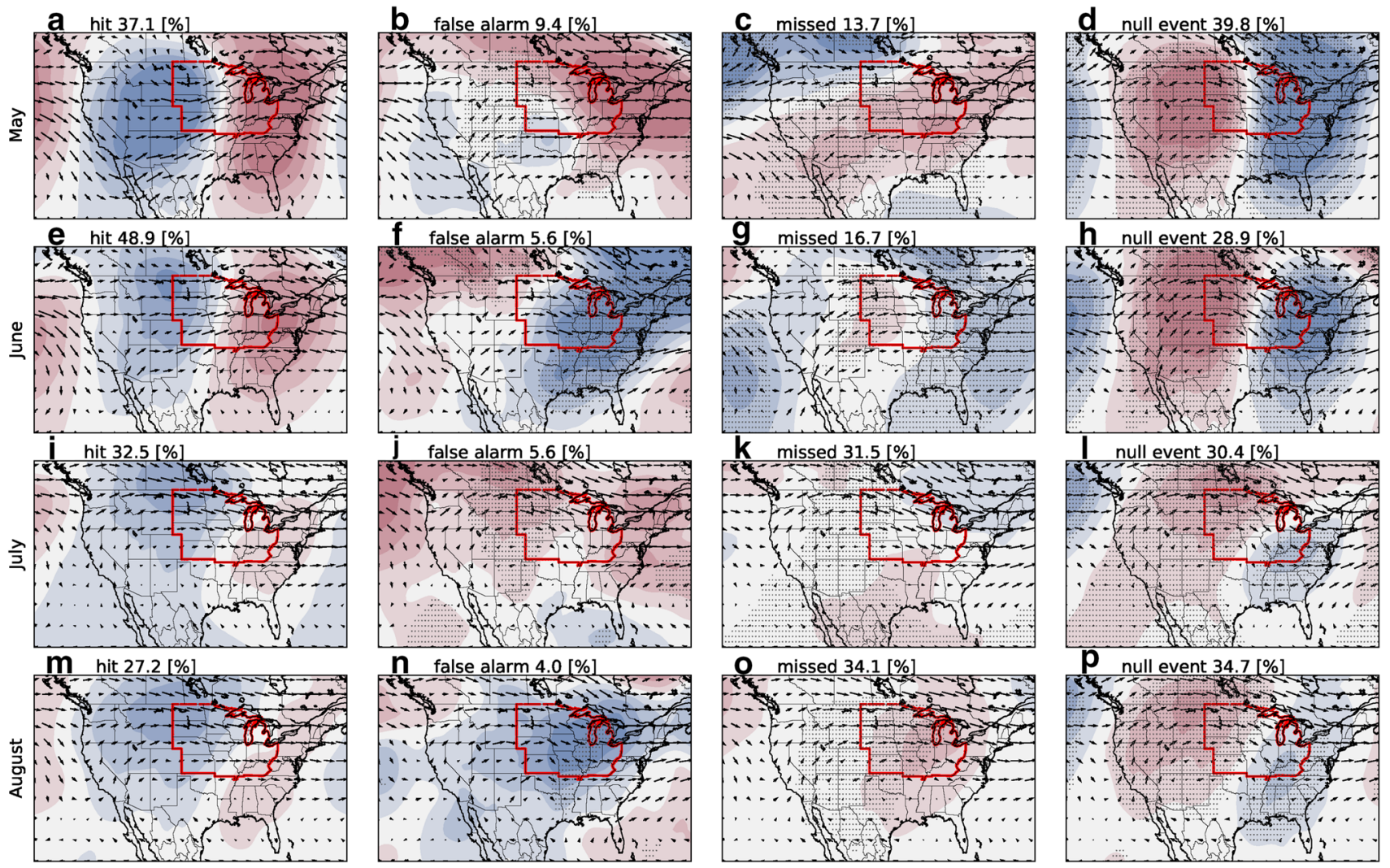

$700 \mathrm{hPa}$ geopotential [m]

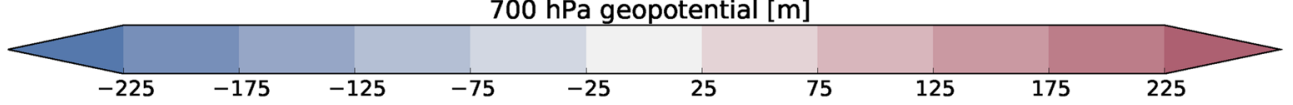

Fig. 13 ERA-Interim $700 \mathrm{hPa}$ geopotential height anomalies and wind on days with observed and modeled MCSs (hit, a, e, i, m), modeled but not observed (false alarm, $\mathbf{b}, \mathbf{f}, \mathbf{j}, \mathbf{n}$ ), observed but not modeled (missed, $\mathbf{c}, \mathbf{g}, \mathbf{k}, \mathbf{o}$ ), and not observed nor modeled (null events, $\mathbf{d}, \mathbf{h}, \mathbf{l}, \mathbf{p})$. The percentage of days within each category are shown above the panels. Results for May, June, July, and August are shown from the top down. Anomalies are calculated compared to monthly climatologies. Hatching shows grid cells that have significantly different mean geopotential heights than those on hit days [5\% confidence level according to the MannWhitney U test (Mann and Whitney 1947)] 


\subsection{Sources of MCS frequency biases}

The significant underestimation of MCS frequency during late summer in the central U.S. is partly related to missing MCS genesis in the High Plains (see Fig. 7). In this section, we investigate ERA-Interim $700 \mathrm{hPa}$ geopotential height anomalies to understand the large-scale conditions that produce or inhibit the development of MCSs in the model during May, June, July, and August (Fig. 13).

Cases where the model is accurately simulating MCSs are typified by negative $700 \mathrm{hPa}$ geopotential height anomalies over the western US and positive anomalies in the eastern US in all investigated months (Fig. 13a, e, i, m). In this situation, MCSs form in the area of negative anomalies and propagate east with the mean flow. In contrast, cases where no MCSs are observed and simulated are typified by positive anomalies in the western US and negative anomalies in the east US (Fig. 13d, h, l, p). On days when the model fails to generate MCSs (missed events), geopotential height anomalies are significantly higher in the MCS development region west (upwind) of the Midwest compared to days with correct simulated MCSs (Fig. 13c, g, k, o). This weather pattern is infrequent in May (14\%) but doubles in frequency during July and August (31 and $34 \%$ ) due to the generally weaker large scale forcing in late summer and the strengthening of the subtropical ridge's influence on the central U.S. The results are very similar if the $500 \mathrm{hPa}$ geopotential height is analyzed. Similar contrasting skills between moderate and weak synoptic forcing have been previously reported in short-term convection-permitting simulations of US warmseason precipitation (Liu et al. 2006).

In summary, our model is underestimating MCSs frequencies in weak synoptic-scale forced conditions that typically occur in late summer. In this situation the correct representation of local-scale processes such as soil-atmosphere interactions, regional-scale wind systems, and mixing in the planetary boundary layer are essential. A summertime warm and dry bias over the central US is fairly common in weather and climate models (e.g., Klein et al. 2006; Ma et al. 2014; Bellprat et al. 2016). We are currently performing sensitivity experiments to find the sources and potential solutions for these biases.

\section{Summary and conclusion}

We evaluate the performance of a north American-scale, convection-permitting climate model to simulate MCSs during the period 2002-2013. The application of a feature based evaluation method provides detailed insights into the model's ability to simulate the frequency and characteristics of MCSs. The model is able to realistically capture the main characteristics of MCSs such as their size, propagation speed, total precipitation volume, and maximum hourly precipitation rates within observational uncertainties in all investigated regions. The realistic simulation of MCS characteristics is a major advantage compared to coarser resolution climate simulations that have to parameterize deep convection (e.g., Chang et al. 2016). These results agree well with results from convection-permitting weather forecast evaluation study (Clark et al. 2014; Davis et al. 2009). The largest biases are found in the model's ability to reproduce the frequency of MCSs. In the Southeast and the MidAtlantic region, MCS frequency is up to $70 \%$ overestimated during JJA. Similar overestimations are found in convectionpermitting weather forecasting models in all US regions (Johnson and Wang 2012; Clark et al. 2014). Different from forecasting biases are the $50 \%$ underestimation of MCSs in the central US during late summer.

Assessing the sources of MCS frequency biases is critically important for future studies. The central Great Plains are an area of especially strong land-atmosphere coupling (Koster et al. 2004). An erroneous representation of land surface processes can lead to a loss of soil moisture in this region resulting in a too dry boundary layer and a reduction of MCS genesis. In particular, the surface energy balance and the effect of including groundwater and irrigation should be further studied. Also, the effect of model grid spacing on MCS genesis and dynamics is not well understood and the representation of shallow convection and turbulence need further exploration.

The accurate simulation of MCSs has significant societal benefits since MCSs produce hazardous weather events that cause 20 billion US\$ of economic losses each year in the US with steadily increasing trends (Munich 2015). CPCSs can provide valuable insights into MCS dynamics and precipitation and will allow unprecedented insights into their changes in response to climate change.

Acknowledgements NCAR is funded by the National Science Foundation and this work was partially supported by the Research Partnership to Secure Energy for America (RPSEA), the NSF EASM Grant AGS-1048829, the US Army Corps of Engineers (USACE) Climate Preparedness and Resilience Program, and NCAR's Water System program. We thank the ECMWF, and NCDC for making available their datasets. Computer resources were provided by the Computational and Information Systems Laboratory (NCAR Community Computing; http://n2t.net/ark:/85065/d7wd3xhc).

Open Access This article is distributed under the terms of the Creative Commons Attribution 4.0 International License (http://creativecommons.org/licenses/by/4.0/), which permits unrestricted use, distribution, and reproduction in any medium, provided you give appropriate credit to the original author(s) and the source, provide a link to the Creative Commons license, and indicate if changes were made. 


\section{References}

Bellprat O, Kotlarski S, Lüthi D, De Elía R, Frigon A, Laprise R, Schär C (2016) Objective calibration of regional climate models: application over Europe and North America. J Clim 29(2):819-838

Brisson E, Demuzere M, van Lipzig NP (2015) Modelling strategies for performing convection-permitting climate simulations. Meteorol Z. doi:10.1127/metz/2015/0598

Bryan GH, Morrison H (2012) Sensitivity of a simulated squall line to horizontal resolution and parameterization of microphysics. Mon Weather Rev 140(1):202-225

Chang W, Stein M, Wang J, Kotamarthi VR, Moyer E (2016) Changes in spatio-temporal precipitation patterns in changing climate conditions. J Clim. doi:10.1175/JCLI-D-15-0844.1

Clark AJ, Weiss SJ, Kain JS, Jirak IL, Coniglio M, Melick CJ, Siewert C, Sobash RA, Marsh PT, Dean AR et al (2012) An overview of the 2010 hazardous weather testbed experimental forecast program spring experiment. Bull Am Meteorol Soc 93(1):55

Clark AJ, Bullock RG, Jensen TL, Xue M, Kong F (2014) Application of object-based time-domain diagnostics for tracking precipitation systems in convection-allowing models. Weather Forecast 29(3):517-542

Cleveland WS (1979) Robust locally weighted regression and smoothing scatterplots. J Am Stat Assoc 74(368):829-836

Dai A, Giorgi F, Trenberth KE (1999) Observed and model-simulated diurnal cycles of precipitation over the contiguous United States. J Geophys Res 104(D6):6377-6402

Davis C, Brown B, Bullock R (2006) Object-based verification of precipitation forecasts. Part I: Methodology and application to mesoscale rain areas. Mon Weather Rev 134(7):1772-1784

Davis CA, Brown BG, Bullock R, Halley-Gotway J (2009) The method for object-based diagnostic evaluation (MODE) applied to numerical forecasts from the $2005 \mathrm{NSSL} / \mathrm{SPC}$ spring program. Weather Forecast 24(5):1252-1267

Dee D, Uppala S, Simmons A, Berrisford P, Poli P, Kobayashi S, Andrae U, Balmaseda M, Balsamo G, Bauer P et al (2011) The ERA-interim reanalysis: configuration and performance of the data assimilation system. Q J R Meteorol Soc 137(656):553-597. doi:10.1002/qj.828

Déqué M, Rowell D, Lüthi D, Giorgi F, Christensen J, Rockel B, Jacob D, Kjellström E, De Castro M, van den Hurk B (2007) An intercomparison of regional climate simulations for Europe: assessing uncertainties in model projections. Clim Change 81(1):53-70

Doneaud A, Ionescu-Niscov S, Priegnitz DL, Smith PL (1984) The area-time integral as an indicator for convective rain volumes. J Clim Appl Meteorol 23(4):555-561

Doswell CA III, Brooks HE, Maddox RA (1996) Flash flood forecasting: an ingredients-based methodology. Weather Forecast 11(4):560-581

Duchon CE, Essenberg GR (2001) Comparative rainfall observations from pit and aboveground rain gauges with and without wind shields. Water Resour Res 37(12):3253-3263

Feng Z, Leung LR, Hagos S, Houze RA, Burleyson CD, Balaguru K (2016) More frequent intense and long-lived storms dominate the springtime trend in central US rainfall. Nat Commun 7. doi:10.1038/ncomms13429

Fulton RA, Breidenbach JP, Seo DJ, Miller DA, O'Bannon T (1998) The wsr-88d rainfall algorithm. Weather Forecast 13(2):377-395

Hong SY, Noh Y, Dudhia J (2006) A new vertical diffusion package with an explicit treatment of entrainment processes. Mon Weather Rev 134(9):2318-2341

Houze RA (2004) Mesoscale convective systems. Rev Geophys 42(4). doi:10.1029/2004RG000150

Iacono MJ, Delamere JS, Mlawer EJ, Shephard MW, Clough SA, Collins WD (2008) Radiative forcing by long-lived greenhouse gases: calculations with the AER radiative transfer models. J Geophys Res Atmos 113(D13). doi:10.1029/2008JD009944

Ikeda K, Rasmussen R, Liu C, Gochis D, Yates D, Chen F, Tewari M, Barlage M, Dudhia J, Miller K et al (2010) Simulation of seasonal snowfall over Colorado. Atmos Res 97(4):462-477

Jacob D, Petersen J, Eggert B, Alias A, Christensen OB, Bouwer LM, Braun A, Colette A, Déqué M, Georgievski G et al (2014) EUROCORDEX: new high-resolution climate change projections for European impact research. Reg Environ Change 14(2):563-578

Jiang X, Lau NC, Klein SA (2006) Role of eastward propagating convection systems in the diurnal cycle and seasonal mean of summertime rainfall over the US Great Plains. Geophys Res Lett 33(19). doi:10.1029/2006GL027022

Johnson A, Wang X (2012) Verification and calibration of neighborhood and object-based probabilistic precipitation forecasts from a multimodel convection-allowing ensemble. Mon Weather Rev 140(9):3054-3077

Klein SA, Jiang X, Boyle J, Malyshev S, Xie S (2006) Diagnosis of the summertime warm and dry bias over the US Southern Great Plains in the GFDL climate model using a weather forecasting approach. Geophys Res Lett 33(18). doi:10.1029/2006GL027567

Koster RD, Dirmeyer PA, Guo Z, Bonan G, Chan E, Cox P, Gordon C, Kanae S, Kowalczyk E, Lawrence D et al (2004) Regions of strong coupling between soil moisture and precipitation. Science 305(5687):1138-1140

Kunkel KE, Easterling DR, Kristovich DA, Gleason B, Stoecker L, Smith R (2012) Meteorological causes of the secular variations in observed extreme precipitation events for the conterminous United States. J Hydrometeorol 13(3):1131-1141

Liu C, Moncrieff MW, Tuttle JD, Carbone RE (2006) Explicit and parameterized episodes of warm-season precipitation over the continental United States. Adv Atmos Sci 23(1):91-105

Liu C, Ikeda K, Thompson G, Rasmussen R, Dudhia J (2011) Highresolution simulations of wintertime precipitation in the Colorado Headwaters region: sensitivity to physics parameterizations. Mon Weather Rev 139(11):3533-3553

Liu C, Ikeda K, Rasmussen R, Barlage M, Thompson G, Newman AJ, Prein AF, Chen F, Chen L, Clark M, Dai A, Dudhia J, Eidhammer T, Gochis D, Gutmann E, Kurkute S, Li Y, Yates D (2016) Continental-scale convection-permitting modeling of the current and future climate of North America. Clim Dyn 23(1):91-105

Lopez RE, Blanchard DO, Holle RL, Thomas JL, Atlas D, Rosenfeld D (1989) J Appl Meteorol 28(11):1162-1175

Ma HY, Xie S, Klein S, Williams K, Boyle J, Bony S, Douville H, Fermepin S, Medeiros B, Tyteca S et al (2014) On the correspondence between mean forecast errors and climate errors in CMIP5 models. J Clim 27(4):1781-1798

Maddox RA (1980) Meoscale convective complexes. Bull Am Meteorol Soc 61(11):1374-1387

Mann HB, Whitney DR (1947) On a test of whether one of two random variables is stochastically larger than the other. Ann Math Stat 18(1):50-60

Miguez-Macho G, Stenchikov GL, Robock A (2004) Spectral nudging to eliminate the effects of domain position and geometry in regional climate model simulations. J Geophys Res Atmos 109(D13). doi:10.1029/2003JD004495

Mittermaier M, Bullock R (2013) Using mode to explore the spatial and temporal characteristics of cloud cover forecasts from highresolution nwp models. Meteorol Appl 20(2):187-196

Munich RE (2015) Natural catastrophes 2015 analyses, assessments, positions. 2016 issue. https://www.munichre.com/site/touchpublications/get/documents_E1273659874/mr/assetpool.shared/ Documents/5_Touch/_Publications/302-08875_en.pdf. Accessed 16 Oct 2017 
Nelson BR, Prat OP, Seo DJ, Habib E (2016) Assessment and implications of NCEP stage IV quantitative precipitation estimates for product intercomparisons. Weather Forecast 31(2):371-394

Niu GY, Yang ZL, Mitchell KE, Chen F, Ek MB, Barlage M, Kumar A, Manning K, Niyogi D, Rosero E et al (2011) The community Noah land surface model with multiparameterization options (Noah-MP): 1. Model description and evaluation with local-scale measurements. J Geophys Res Atmos 116(D12). doi:10.1029/20 10JD015139

Perkins S, Pitman A, Holbrook N, McAneney J (2007) Evaluation of the AR4 climate models' simulated daily maximum temperature, minimum temperature, and precipitation over Australia using probability density functions. J Clim 20(17):4356-4376

Prein A, Gobiet A, Suklitsch M, Truhetz H, Awan N, Keuler K, Georgievski G (2013a) Added value of convection permitting seasonal simulations. Clim Dyn 41(9-10):2655-2677

Prein AF, Holland GJ, Rasmussen RM, Done J, Ikeda K, Clark MP, Liu CH (2013b) Importance of regional climate model grid spacing for the simulation of heavy precipitation in the Colorado headwaters. J Clim 26(13):4848-4857

Prein AF, Langhans W, Fosser G, Ferrone A, Ban N, Goergen K, Keller M, Tölle M, Gutjahr O, Feser F et al (2015) A review on regional convection-permitting climate modeling: demonstrations, prospects, and challenges. Rev Geophys 53(2):323-361

Prein AF, Rasmussen RM, Ikeda K, Liu C, Clark MP, Holland GJ (2017) The future intensification of hourly precipitation extremes. Nat Clim Change 7:48-52

Rotunno R, Klemp JB, Weisman ML (1988) A theory for strong, longlived squall lines. J Atmos Sci 45(3):463-485
Skamarock WC, Klemp JB (2008) A time-split nonhydrostatic atmospheric model for weather research and forecasting applications. J Comput Phys 227(7):3465-3485

Taylor KE, Stouffer RJ, Meehl GA (2012) An overview of CMIP5 and the experiment design. Bull Am Meteorol Soc 93(4):485

Thompson G, Eidhammer T (2014) A study of aerosol impacts on clouds and precipitation development in a large winter cyclone. $\mathrm{J}$ Atmos Sci 71(10):3636-3658

von Storch H, Langenberg H, Feser F (2000) A spectral nudging technique for dynamical downscaling purposes. Mon Weather Rev 128(10):3664-3673. doi:10.1175/1520-0493(2000)128<3664:ASNTFD>2.0.CO;2

Wang SY, Chen TC, Correia J (2011) Climatology of summer midtropospheric perturbations in the US northern plains. Part I: influence on northwest flow severe weather outbreaks. Clim Dyn 36(3-4):793-810

Wernli H, Paulat M, Hagen M, Frei C (2008) SAL—a novel quality measure for the verification of quantitative precipitation forecasts. Mon Weather Rev 136(11):4470-4487

Yang S, Smith EA (2008) Convective-stratiform precipitation variability at seasonal scale from $8 \mathrm{yr}$ of TRMM observations: implications for multiple modes of diurnal variability. J Clim 21(16):4087-4114

Zhang J, Howard K, Langston C, Kaney B, Qi Y, Tang L, Grams H, Wang Y, Cocks S, Martinaitis S et al (2016) Multi-radar multisensor (MRMS) quantitative precipitation estimation: initial operating capabilities. Bull Am Meteorol Soc 97(4):621-638 